\title{
Evaluation for the effect of non-stationary nutrient transport on the coastal seaweed cultivation in western Japan
}

\author{
M. Saito ${ }^{1}$, S. Onodera ${ }^{2}$, G. Hidaka ${ }^{3, *}$, and M. Tokumasu ${ }^{4}$ \\ ${ }^{1}$ Graduate School of Environmental and Life Science, Okayama University, Okayama, Japan \\ ${ }^{2}$ Graduate School of Integrated Arts and Sciences, Hiroshima University, Hiroshima, Japan \\ ${ }^{3}$ Faculty of Integrated Arts and Sciences, Hiroshima University, Hiroshima, Japan \\ ${ }^{4}$ Saijo city government office, Ehime, Japan \\ *now at: Miyazaki prefectural government office, Miyazaki, Japan \\ Correspondence to: M. Saito (misaito@okayama-u.ac.jp)
}

Received: 11 March 2015 - Accepted: 11 March 2015 - Published: 12 June 2015

\begin{abstract}
In order to evaluate the effects of non-stationary nutrient transport on the coastal seaweed cultivation, variations of the seaweed yield, nutrient condition of seawater, rainfall and nutrient transport from the river, observed over the last 40 years were examined to characterize the long-term trends and the influencing factors on the variation of seaweed yield. The results show that seaweed yield increased until 1973, then decreased in recent years. The recent condition of nutrients in seawater is relatively severe for seaweed farming. The results suggest that river-derived nutrient supply to coastal area will decrease further by the decrease of river discharge. For the future prospect, it is important to evaluate the variation of other nutrient supply such as from groundwater, offshore or bottom sediment as well as river discharge.
\end{abstract}

\section{Introduction}

Coastal seas and estuaries are characterized by significantly high biological production and biodiversity where freshwater with higher nutrients meets saltwater (Statham, 2012). It is also an important area for coastal aquacultures such as the seaweed farming. However, the river-derived nutrient supply is unsteady and is closely related to the environmental changes such as variation of precipitation and land use (Eyre, 2000). In the case of Seto Inland Sea of Japan, previous studies reported that fish catches and yields of edible seaweed (Laver) have been decreasing in recent years (Yamamoto, 2003; Tada et al., 2010). It is one of the critical problems in the coastal fisheries in Japan. For the sustainable fishery production, it is important to evaluate and predict the effect of non-stationary nutrient transport from land on the coastal environment.

In the present study, we aim to evaluate the effects of variation in rainfall and nutrient transport from the river on the nutrient environment and the seaweed farming in the last 40 years in the coastal area of the Seto Inland Sea.

\section{Study area}

The study area is the coastal area of southern part of HiuchiNada Bay. It is about $50 \mathrm{~km} \times 30 \mathrm{~km}$ with an average depth of approximately $20 \mathrm{~m}$, and is a semi-enclosed bay in central part of Seto Inland Sea in western Japan (Fig. 1a, b). Seto Inland Sea is the largest semi-enclosed coastal sea in Japan with significant influence of freshwater inputs. Kamo River is one of the main inflowing river to the study area with about $202 \mathrm{~km}^{2}$ of watershed (Fig. 1c). The headstream area of it is Mt. Ishizuchi which is the highest mountain (max. 1982 m AMSL) in western Japan. In the river mouth area of Kamo River, edible seaweeds (laver, green laver) have been cultivated for more than 170 years. It is one of the Japan's leading production area of green laver. However, Kamo River water mostly infiltrates to underground before it reaches the 


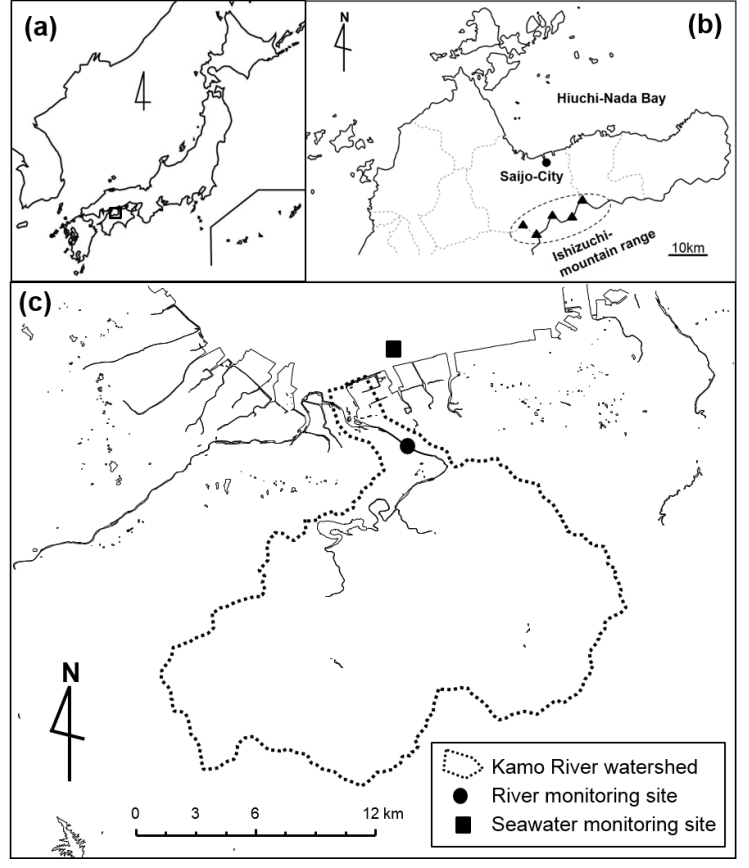

Figure 1. Location of study area.

river mouth during the base flow period. Whereas, the study area is characterized by abundant volume of groundwater in the confined aquifer system which is partly recharged by the Kamo River water.

\section{Methods}

We obtained the pre-existing datasets on annual yield of laver in the study area (1965-2011) from the fishery association of Saijo city, nutrient concentrations of coastal seawater (1972-2012) at the monitoring station (Fig. 1c) from the Research institute for cultivation and resource in the coastal area of Ehime prefecture, annual precipitation (19762012) at the monitoring station in Saijo city located about 4 m AMSL (Fig. 1c) from Japan Metrological Agency (JMA) (http://www.jma.go.jp/jma/index.html), discharge and nutrient concentrations of Kamo River (1983-2012) at the monitoring station (Fig. 1c) from the Ehime prefectural government, days of water reaching the river mouth of Kamo River (1978-2012) from Saijo city government, respectively. The original dataset of seaweed yield was recorded as number of dried sheets. Therefore, we converted it to the dry weight assuming that one sheet is 3 gram which is average weight in Japan. Nutrient flux of Kamo River was estimated from discharge and concentrations of nutrients. Using these datasets, we confirmed the long-term trends on respective components. We also tried to examine the influencing factors on the variation of seaweed yield.

\section{Results and discussion}

\subsection{Long-term variation of seaweed yield and nutrient supply from land to coastal area}

Figure 2 shows the variation in annual yield of seaweed in the coastal area of Saijo city (Fig. 1b, c) from 1965-2011. The yield was in the peak in 1973, since then it has totally on a decreasing trend in recent years. Figure 3 shows the variations in dissolved inorganic nitrogen (DIN) (a), dissolved inorganic phosphorus (DIP) (b), dissolved silica (DSi) (c) and ratios between nitrogen and phosphorus $(\mathrm{N} / \mathrm{P})$ and nitrogen and silica $(\mathrm{N} / \mathrm{Si})(\mathrm{d})$ in the coastal seawater from 1972-2012. DIN and DIP show the decreasing trend totally, while DSi shows the increasing trend in recent years. In the previous research, lowering concentrations of nitrogen $\left(<7 \mu \mathrm{mol} \mathrm{L}^{-1}\right)$ and phosphorus $\left(<0.4 \mu \mathrm{mol} \mathrm{L}^{-1}\right)$ in seawater causes change in color of seaweeds and decrease in quality (Koike and Fuchigami, 2013). The results indicate that both of DIN and DIP fall below the lower limits in many periods, especially the decrease of DIP is more significant in recent 20 years (Fig. 3a, b). These results indicate that recent condition of nutrient in seawater is relatively severe for the seaweed farming.

The variation of annual rainfall in the Saijo city from 1976-2012 is shown in Fig. 4a. It shows slightly increasing trend during the period with relatively large annual change. Especially, 1976, 1980, 1993 and 2004 was the wet years with more than $2000 \mathrm{~mm} \mathrm{yr}^{-1}$, while 1978,1984 , 1986, 1994, 2002 and 2005 was the dry years with about $1000 \mathrm{~mm} \mathrm{yr}^{-1}$, respectively. Figure $4 \mathrm{~b}$ shows the variation in number of days exceeded $100 \mathrm{~mm}$ of daily rainfall. It indicates the large-scale rainfall event has slightly decreased during the period. The yield of seaweed tends to decrease significantly in or following the dry year (Figs. 2, 4a). It suggests the variation of nutrient supply caused by climate change influences on the yield of seaweed in the coastal area.

Figure 5 shows the variations in discharge (a), concentrations of total nitrogen (TN) and total phosphorus (TP) (b) and estimated fluxes of TN and TP (c) from 1972-2012. The discharge show the peak in early 1970s (Fig. 5a), however it is not supported by the rainfall data near the coastal area (Fig. 4). It suggest rainfall in more upstream area influenced to the river discharge. Though the river discharge contains many missing data, the fluxes of TN and TP were estimated to be decreased in recent years (Fig. 5c). The concentration of TN has increased slightly during the period, while TP has decreased significantly since 1996 (Fig. 5b). It possibly influences on the lowering concentration of DIP in the coastal seawater (Fig. 3b). Figure 6 shows days of water reaching the river mouth of Kamo River from 1978 to 2012. As previously mentioned, Kamo River water usually do not reach to the river mouth during the base flow period. The result shows totally decreasing trend, however it is more significant in last 10 years. 


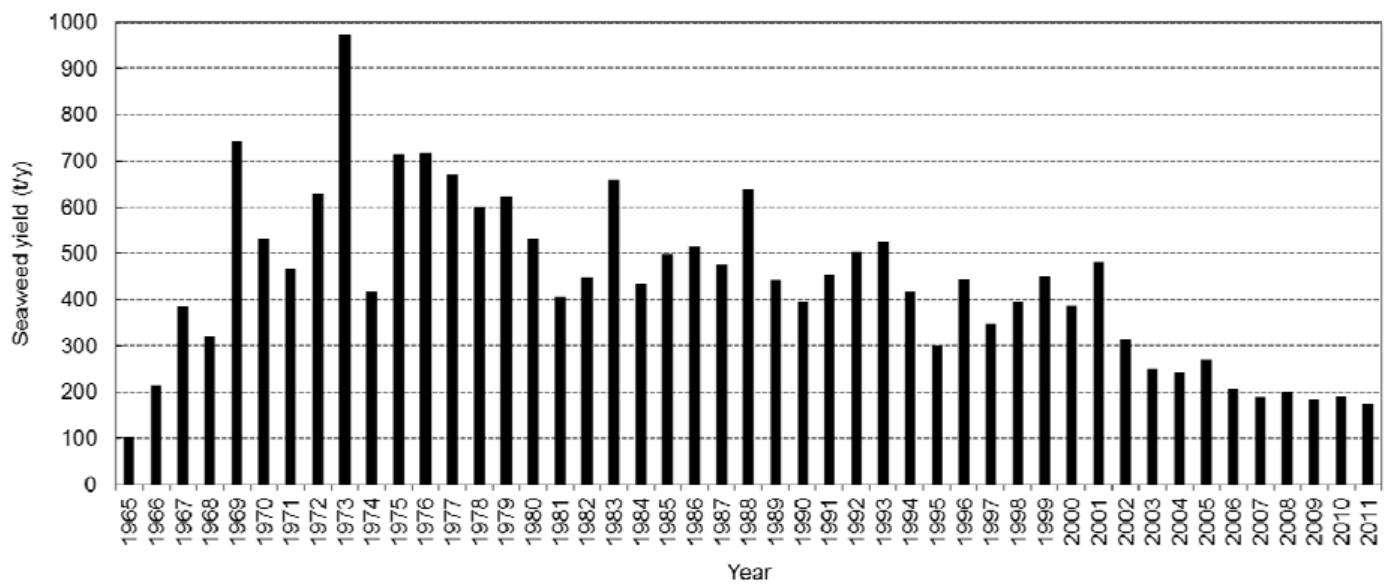

Figure 2. Variation in annual yield of seaweed in the coastal area of Saijo city from 1965-2011.

\subsection{Effect of land-derived nutrients on seaweed farming and future outlook}

Our results indicates that levels of DIN and DIP in seawater are in severe condition for the seaweed farming recently. Especially DIP will be a more critical factor for limiting seaweed cultivation. Besides, $\mathrm{N} / \mathrm{Si}$ ratio tends to below the Redfield ratio $(\mathrm{N}: \mathrm{Si}=1: 1)$ (Redfield, 1934) in recent years (Fig. 3d). It suggests the competition between seaweeds and diatoms will increase in the future.

The yields of seaweed tend to decrease in or following the dry year (Figs. 2, 4a). Onodera et al. (2007) reported that annual rainfall has been decreasing over the last five decades in whole coastal area of Seto Inland Sea, which suggests increased frequency of drought in the future. Figure 7 shows the relation between annual rainfall and seaweed yield. From 1976-2002, the yields tend to increase with the increase of rainfall. However, it keeps falling below $300 \mathrm{t} \mathrm{yr}^{-1}$ since about 2003 and has no correlation with rainfall. Tada et al. (2010) also pointed out the similar decorrelation since 2002 in Harima-Nada Bay in Seto Inland Sea. On the cause of this, we need to consider other factors such as the variations of nutrient supply from offshore or bottom sediment.

The results also suggest that river-derived nutrient supply to coastal area will decrease further in the future by the decrease of river discharge (Figs. 5, 6), meanwhile the river water infiltrates to underground and recharges groundwater. It suggests that we need to evaluate the nutrient supply from groundwater to the coastal area (Saito et al., 2011) as well as river water and maintain it for the sustainable seaweed farming in the future.

\section{Concluding remarks}

To evaluate the effects of non-stationary nutrient transport on the coastal seaweed farming, variations of the seaweed yield, nutrient condition of seawater, rainfall and nutrient transport from the river were confirmed for the last 40 years and examined the long-term trends and the influencing factors on the variation of seaweed yield. The results indicate that seaweed yield has totally increased until 1973, since then decreased in recent years. The condition of nutrients in seawater is relatively severe for the seaweed farming recently. The results suggest that river-derived nutrient supply to coastal area will decrease further by the decrease of river discharge. For the future prospect, we need to evaluate the variation of other nutrient supply from such as groundwater, offshore or bottom sediment as well as river discharge. 

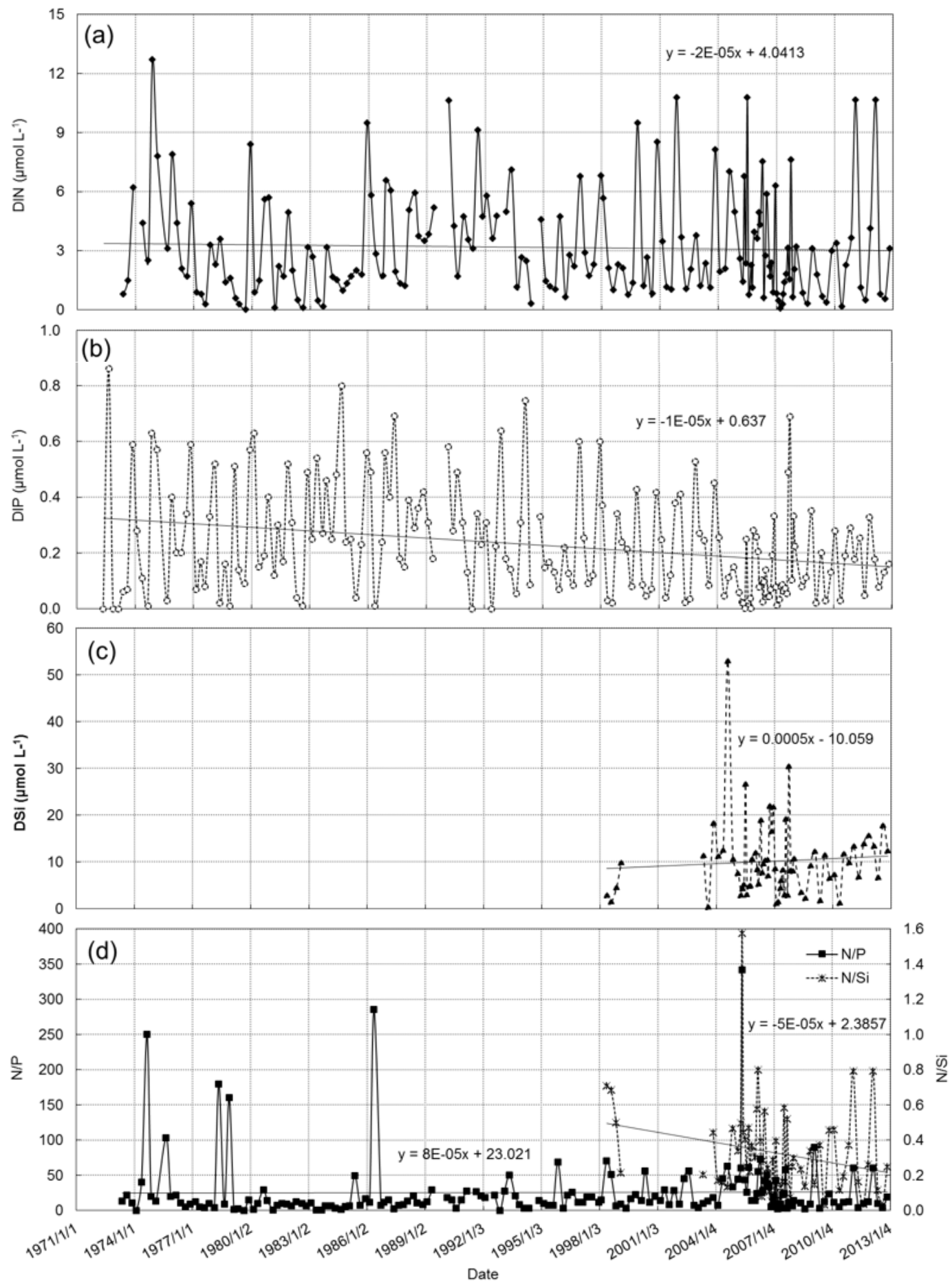

Figure 3. Variations in dissolved inorganic nitrogen (DIN) (a), dissolved inorganic phosphorus (DIP) (b), dissolved silica (DSi) (c) and ratios between nitrogen and phosphorus $(\mathrm{N} / \mathrm{P})$ and nitrogen and silica $(\mathrm{N} / \mathrm{Si})(\mathbf{d})$ in the coastal seawater from 1972-2012. 

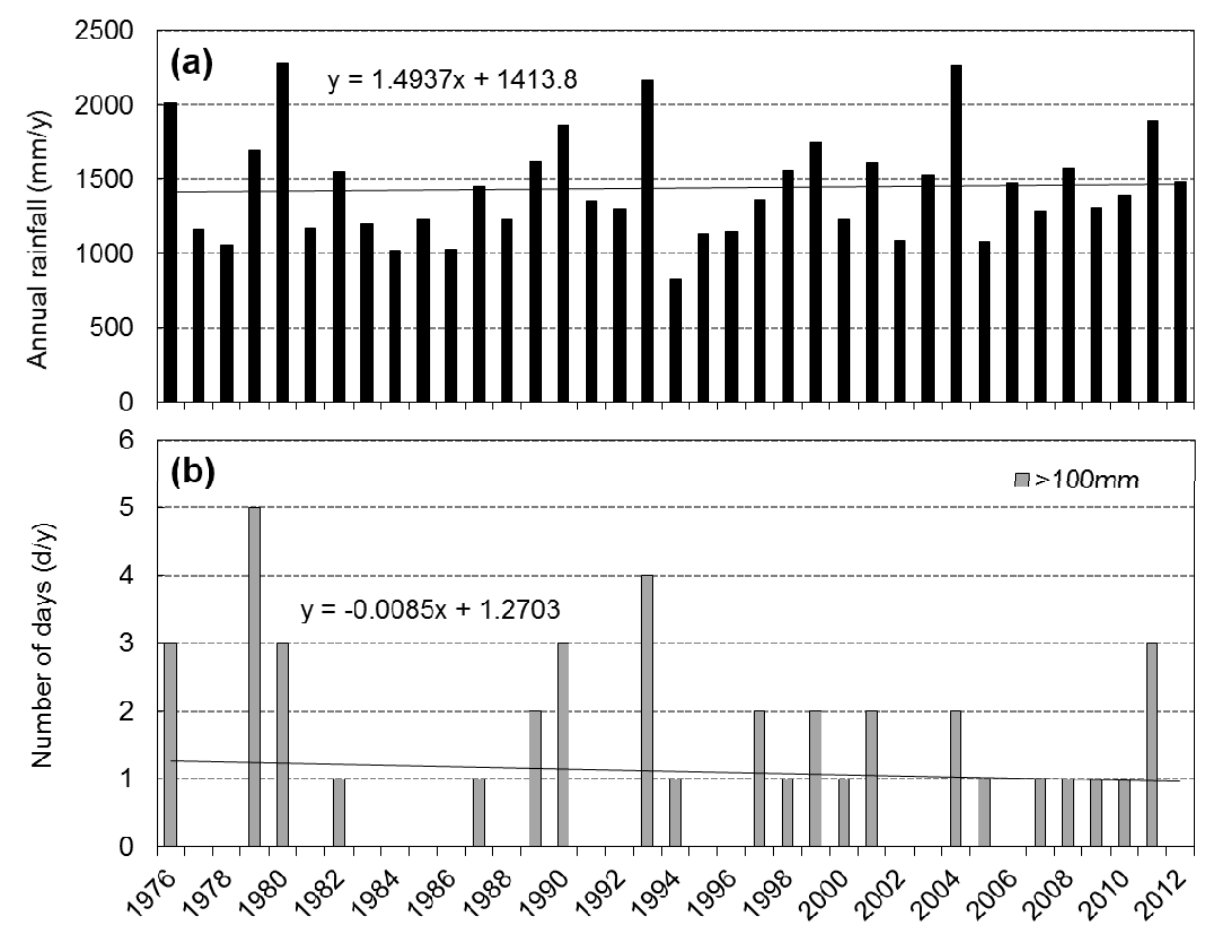

Figure 4. Variation of annual rainfall in the Saijo city from 1976-2012 (a) and number of days exceeded $100 \mathrm{~mm}$ of daily rainfall (b).

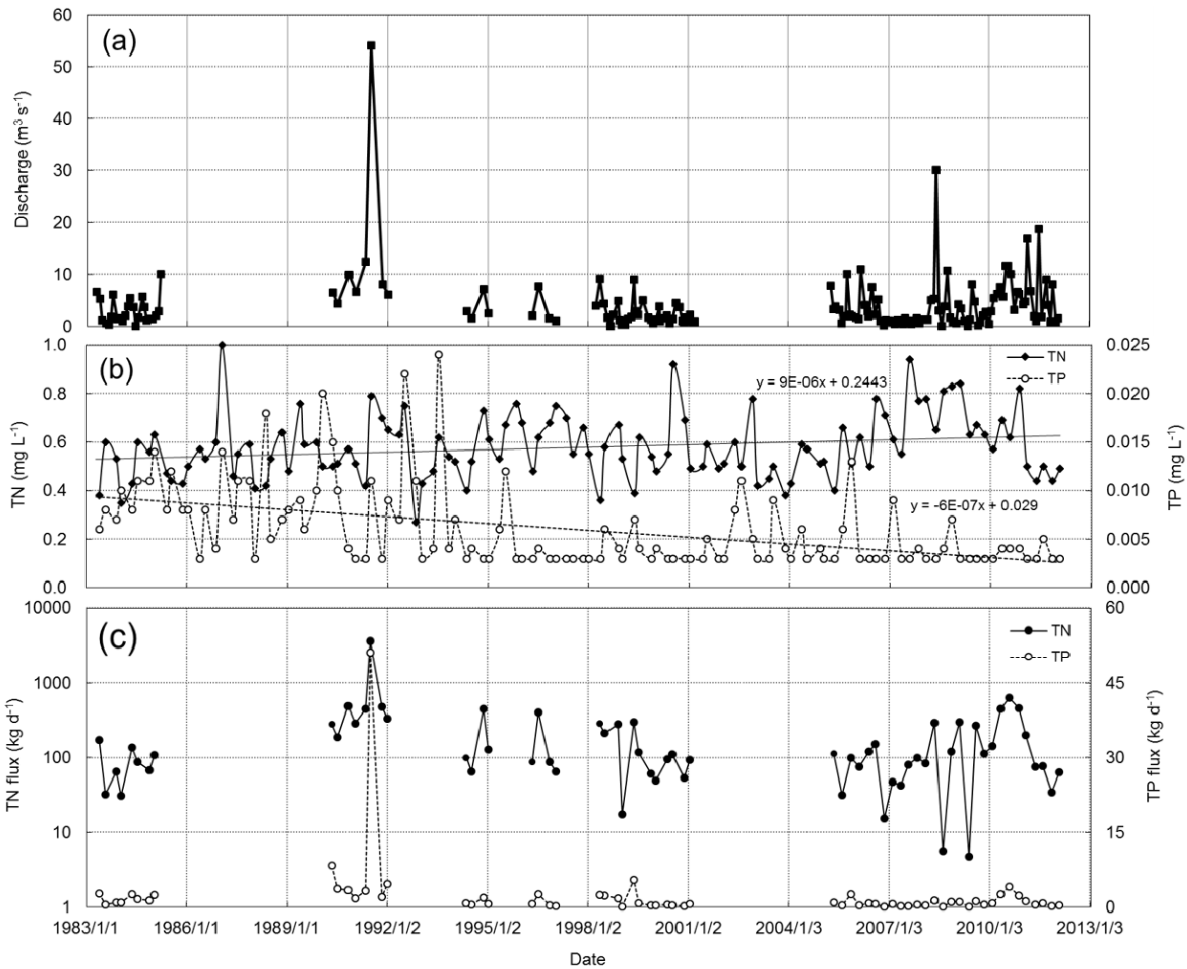

Figure 5. Variations in discharge (a), concentrations of total nitrogen (TN) and total phosphorus (TP) (b) and estimated fluxes of TN and TP (c) from 1972-2012. 


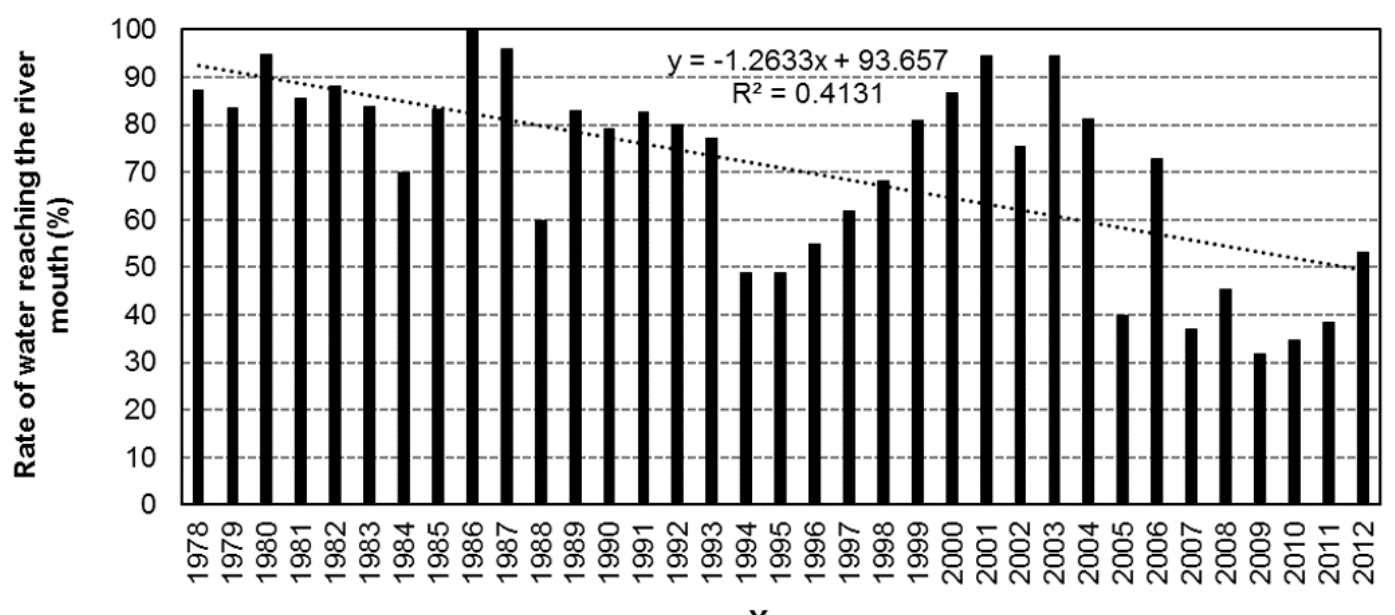

Figure 6. Days of water reaching the river mouth of Kamo River from 1978-2012.

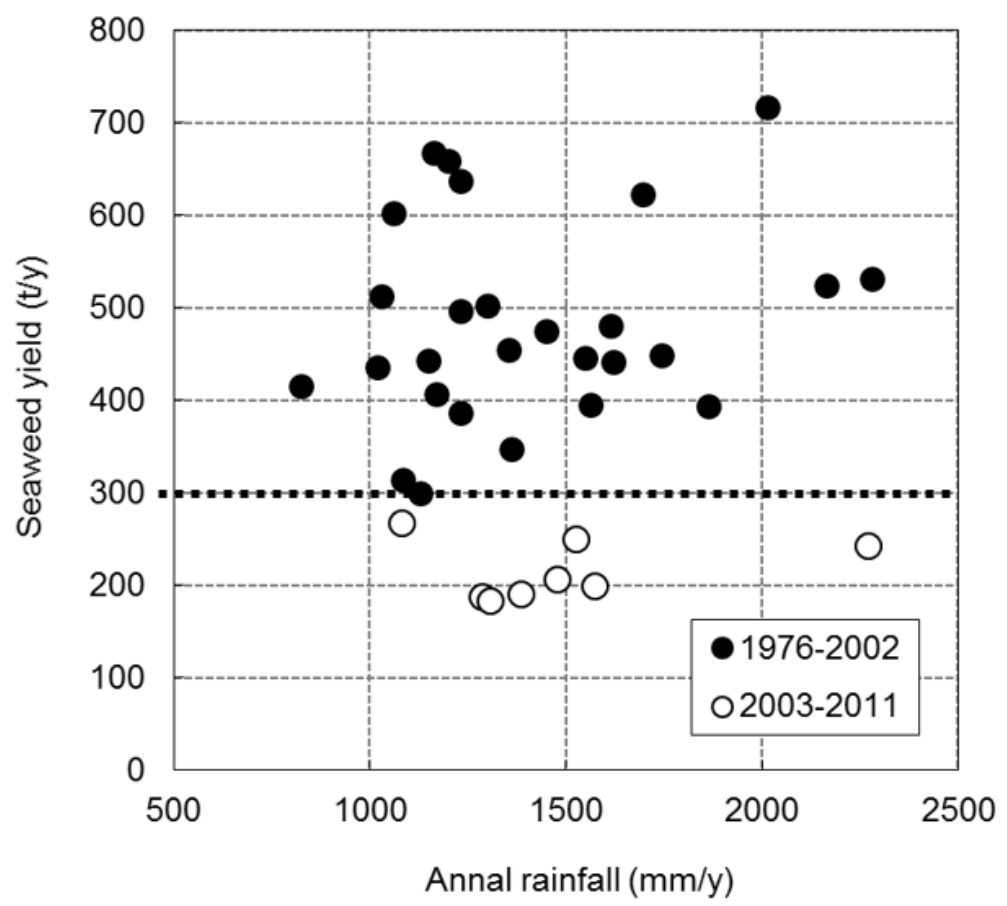

Figure 7. The relation between annual rainfall and seaweed yield. 
Acknowledgements. This study was financially supported by the research grant of River foundation in Japan (Kasen Zaidan) in 2012 and the Grant-in-Aid for JSPS fellows by JSPS from 2011-2012. The authors thank the staffs of the Research institute for cultivation and resource in the coastal area of Ehime prefecture, the fishery association of Saijo city and the Ehime prefectural government for providing information and continuing support.

\section{References}

Eyre, B. D.: Regional evaluation of nutrient transformation and phytoplankton growth in nine river-dominated sub-tropical east Australian estuaries, Mar. Ecol. Prog. Ser., 205, 61-83, 2000.

Koike, M. and Fuchigami, T.: The effect of lack of dissolved inorganic phosphorus on Pyropia yezoensis, Bull. Fukuoka Fisheries Mar. Technol. Res. Cent., 23, 33-42, 2013 (in Japanese).
Onodera, S., Sawano, M., Saito, M., and Takahashi, H.: Effect of frequent storms on nutrient discharge in a mountainous coastal catchment, western Japan, in: Water Quality and Sediment behaviour of the Future: Predictions for the 21st Century, edited by: Webb, B. W. and de Boer, D., IAHS Publ., IAHS Press, Wallingford, UK, 314, 108-116, 2007.

Redfield, A. C.: On the proportions of organic derivatives in seawater and their relation to the composition of plankton, in: Johnstone Memorial Volume, 176-192, Univ. of Liverpool, Liverpool, UK, 1934.

Saito, M., Guo, X., Onodera, S., Shimizu, Y., Kato, Y., Tokumasu, M., and Takeoka, H.: Spatial variation of submarine groundwater discharge (SGD) in the central part of Seto Inland Sea, Interdisciplinary Stud. Environ. Chem., 5, 117-123, 2011.

Statham, P. J.: Nutrients in estuaries- An overview \& the potential impacts of climate change, Sci. Total Environ., 434, 213-227, 2012.

Tada, K., Fujiwara, M., and Honjo, T.: Water quality and Nori (Porphyra) culture in the Seto Inland Sea, Bunseki Kagaku, 59, 945955, 2010 (in Japanese).

Yamamoto, T.: The Seto Inland Sea-eutrophic or oligotrophic?, Mar. Poll. Bull., 47, 37-42, 2003. 